\title{
The Manifestation of Anxiety as Repercussion of COVID-19: A Survey of Medical Practitioner's Opinion
}

\author{
Dinesh Kumar ${ }^{1}$ - Goma Bajaj ${ }^{2}$ - Savarna ${ }^{3}$ - Anupama Bhoria ${ }^{4} \cdot$ Sudipta Banerjee $^{5} \cdot$ Pawan Yadav $^{6} \cdot$ Sunil Kumar $^{7}$. \\ Davinder Kumar ${ }^{8} \cdot$ Randhir Singh $^{9} \cdot$ Sunil Kumar Madaan ${ }^{10} \cdot$ Jitender Singh ${ }^{11}$ (D)
}

Received: 6 September 2020 / Accepted: 20 April 2021 / Published online: 4 May 2021

(c) King Fahd University of Petroleum \& Minerals 2021

\begin{abstract}
Anxiety is usually transient in nature, but if the symptoms are severe and persistent in the absence of stressor, then it is considered as anxiety disorder. Corona virus disease 2019 (COVID-19) which was declared as pandemic by World Health Organization in March 2020 affected the lives of human beings worldwide. A panic and anxious situation was created due to the outbreak of COVID-19. Medical health practitioners have been connected with the patients and hence can better speculate the psychology of human beings. The present study was designed to find out the manifestation of anxiety as repercussion of COVID-19 on the basis of opinion of medical practitioners. A survey was conducted among the medical practitioners from India and Bangladesh to find out the possibility of anxiety as after-effect of COVID-19 through questionnaires. Results of the study showed that $95 \%$ medical practitioners were in the view to have chances of anxiety with more possibility to have social anxiety and post-traumatic stress anxiety disorder as a consequence of COVID-19. Female and male genders have equal chances, whereas transgender have lesser chances to have anxiety disorders as a consequence of COVID-19. Population above 50 years age might have maximum chance of having anxiety as after-effect of COVID-19. The study concludes to have chances of anxiety as repercussion of COVID-19.
\end{abstract}

Keywords Anxiety $\cdot$ After-effects $\cdot$ COVID- $19 \cdot$ Corona virus $\cdot$ Medical practitioners

\section{Introduction}

Anxiety is an adaptive reaction to stress which assists the person to cope with the stressful condition. It involves with an unwanted perception of insecurity associated with

Jitender Singh

jitender.kuk@gmail.com

1 Department of Pharmaceutical Sciences, Central University of Haryana, Mahendragarh, Haryana 123031, India

2 MM Institute of Medical Sciences \& Research, Mullana, Ambala, Haryana 133207, India

3 College of Physiotherapy, PGIMS, Pandit Bhagwat Dayal Sharma University of Health Sciences, Rohtak, Haryana 124001, India

4 Government Polytechnic for Women, Sector 10-D, Chandigarh 160011, India

5 Allign Consultancy Services, Kolkata, West Bengal 700001, India

6 Rainbow Multispeciality Hospital, Narnaul, Mahendergarh, Haryana 123001, India apprehension [1,2]. Anxiety is usually transient in nature, but if the symptoms are prolonged and severe in the absence of stressor, then it is considered as an anxiety disorder [3, 4]. Such anxiety disorders are the most common mental disorders experienced by children to the elder human population.

7 ICMR-Regional Medical Research Center Gorakhpur, Gorakhpur, Uttar Pradesh 273013, India

8 Swami Dayanand Post Graduate Institute of Pharmaceutical Sciences, Pandit Bhagwat Dayal Sharma University of Health Sciences, Rohtak, Haryana 124001, India

9 Maharishi Markandeshwar College of Pharmacy, M. M. University, Mullana, Ambala, Haryana 133207, India

10 Stanford Laboratories Pvt. Ltd, Una, Himachal Pradesh 174315, India

11 IEC School of Pharmacy, IEC University, Atal Shiksha Nagar, Kallujhanda, Baddi, District Solan, Himachal Pradesh 174103, India 
The symptoms of anxiety are characterized by fear, stress, high blood pressure, sweating, trembling, etc. About 284 million people experienced anxiety disorder globally in 2017; among them, 179 million were female and 105 million were male [5]. According to a report, the prevalence of anxiety disorders among higher secondary school students in India is $56.8 \%$; among them, $15 \%$ have panic disorders, $13 \%$ develop generalized anxiety disorders, $4 \%$ have separation anxiety, $15.6 \%$ suffer social anxiety, and 9.2\% exhibit school avoidance anxiety [6]. Anxiety disorders may develop from a complex set of factors including genetic, brain chemistry, environment, personality and life events. Various types of anxiety disorders are shown in Table 1 . Barbiturates, benzodiazepines (BZDs), azapirones, norepinephrine, serotoninreuptake inhibitors, monoamine oxidase inhibitors, phenothiazines, etc., are the common class psychotropic drugs [7] used for the treatment of anxiety.

The outbreak of COVID-19 caused by novel Corona virus was declared pandemic by World Health Organization (WHO) which affected the lives of human beings worldwide. It not only affected the economic aspects but also disturbed the routine life of human being to a great extent. According to COVID-19 Situation Report -169 of WHO, the total number of COVID-19 confirmed cases are 19,718,030 including 728,013 deaths, globally in 216 countries, areas or territories [15]. A global lockdown was observed worldwide with the advice of social distancing and frequent hand washing along with certain guidelines issued by the Government of respective countries and $\mathrm{WHO}$ as a precautionary measure against COVID-19. Considering the circumstances arisen due to complete lockdown and panic situation, the present study was designed to find out the consequences of COVID19 on anxiety. Medical Health Practitioners are the primary contact person with the public who can better understand the implications of the panic situations created due to COVID19 and speculate the possibility of anxiety as one of the after-effects. Expert opinion related to theme of the manuscript was taken in the form of questionnaire from the medical practitioners working in various healthcare sectors. Flavonoids like hesperidin, chrysin, naringenin, astilbin, icariin, 7,8-dihydroxyflavone, hyperoside, baicalein, kaempferitrin, luteolin, vitexin, amentoflavone, fisetin, nobiletin, quercetin, etc., have been reported to have actions against oxidative stress and hence can be used as remedy for anxiety disorders [16].

\section{Materials and Methods}

\subsection{Design of the Questionnaire}

A questionnaire was designed to collect information related to anxiety as after-effects of COVID-19 from the medical practitioners. The questionnaire covers the basic information of the respondents with a set of 6 questions. The responses of questions were considered either in the form of "yes" or "no" or based on "score 1-10" as shown in Fig. 1.

\subsection{Plan and Methods of Sampling}

The responses from medical practitioners working in various hospitals and health sectors in India and Bangladesh were collected through email or WhatsApp in the form of questionnaire (Fig. 1). The questions with the response score 1-10 (each point of score equivalent to $10 \%$ ) were given in the questionnaire. First three questions in the questionnaire based on "yes" or "no" responses—are you aware about the pandemic situation of COVID-19, are you aware with the anxiety disorders and do you think anxiety-would be one of the major after-effect of COVID-19. Fourth and Fifth questions were based on score (1-10) to find out the possibility of type of anxiety and age group affected as repercussion of COVID-19. The sixth question was descriptive answer type question kept for any other information related to the study.

\subsection{Data Compiling and Statistical Analysis}

The results were compiled on four major questions-possibility to have anxiety as after effect of COVID-19, possibility of type of anxiety as after-effect of COVID-19, possibility of anxiety after-effect of COVID-19 on gender and possibility of anxiety as after effect of COVID-19 in various age groups. Data have been expressed as mean \pm standard error of mean. The statistical analysis was done under column analysis (column statistics) using GraphPad Prism 5 software.

\section{Results and Discussion}

The study was conducted to find out the manifestation of anxiety as repercussion of COVID-19. Out of 167 respondents approached for participation, 81 responded the questionnaires. Results of the study are shown in Tables 2, 3, and 4 and Figs. 2, 3, 4, and 5. The study was designed in the form of questionnaire to find out the manifestation of anxiety as repercussion of COVID-19. Medical practitioners were taken as the respondents in the study. All participants 


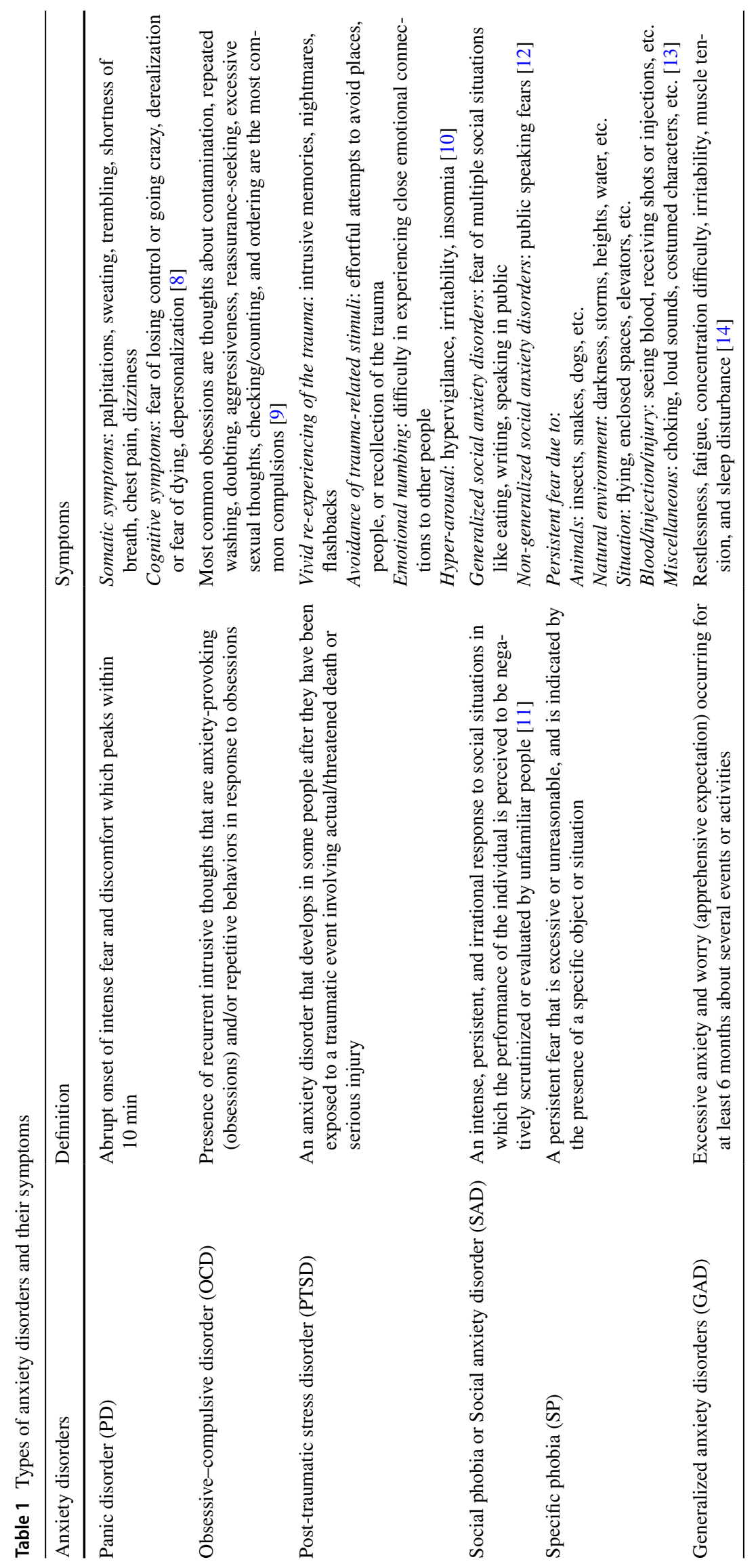

I Springer 
Fig. 1 Format of questionnaire

Study title: Possibility of Human Anxiety as After-effects of COVID-19: A Medical Expert's Opinion

Name of respondent:

Qualification:

Profession:

Total work experience as Medical Officer/Physician:

Affiliation:

Email:

1. Are you aware about the pandemic situation of COVID-19: (Yes/No)

Your response:

2. Are you aware with the anxiety disorders: (Yes/No)

Your response:

3. Do you think anxiety would be one of the major after effects of COVID-19: (Yes/No)

Your response:

4. What type of anxiety might be occurred as a major after-effects of COVID-19 (Score your opinion between 0 to 10 ):

0 score means - not affected, 10 score means $-100 \%$ or Maximum chances to have affected; In between 0-10 (decides the \% of chances to affect with anxiety after COVID-19 as after effect)

\begin{tabular}{|l|l|l|}
\hline S. No. & Type of Anxiety & $\begin{array}{c}\text { Score }(0-10) \\
\text { Your response }\end{array}$ \\
\hline 1 & Generalized anxiety disorders (GAD) & \\
\hline 2 & Panic disorder (PD) & \\
\hline 3 & Obsessive-compulsive disorder (OCD) & \\
\hline 4 & Post-traumatic stress disorder (PTSD) & \\
\hline 5 & Social phobia or Social anxiety disorder (SAD) & \\
\hline 6 & Specific phobia (SP) & \\
\hline
\end{tabular}

5. Which of following populations might be affected with the anxiety disorders after COVD-19 as aftereffects (Score your opinion between 0 to 10 ):

0 score means - not affected, 10 score means $-100 \%$ or Maximum chances to have affected; In between 0-10 (decides the \% of chances to affect with anxiety after COVID-19 as after-effect)

\begin{tabular}{|l|l|l|}
\hline S. No. & \multicolumn{1}{|c|}{ Population age group } & $\begin{array}{l}\text { Chances to have anxiety as } \\
\text { after-effects of COVID-19 } \\
\text { Score (0-10) } \\
\text { Your response }\end{array}$ \\
\hline 1 & Children upto 5 years age group & \\
\hline 2 & Children between 6-10 years age group & \\
\hline 3 & Children between 11-18 years age group & \\
\hline 4 & Person between 19-30 age group & \\
\hline 5 & Person between 31-50 age group & \\
\hline 6 & Person with 51-70 age group & \\
\hline 7 & Person above 70 age group & \\
\hline 8 & Females & \\
\hline 9 & Males & \\
\hline
\end{tabular}

6. Any other information related to the study:

Signature of respondent:

\begin{tabular}{lllllll}
\hline Determinants & \multicolumn{2}{l}{ Type of anxiety } \\
\cline { 2 - 7 } & GAD & PD & OCD & PTSD & SAD & SP \\
\hline No. of values & 80 & 78 & 80 & 80 & 81 & 79 \\
Mean & 5.738 & 4.718 & 4.250 & 5.488 & 6.012 & 4.633 \\
25\% Percentile & 3.000 & 3.000 & 2.250 & 4.000 & 4.000 & 2.000 \\
Median & 6.000 & 5.000 & 4.000 & 5.000 & 6.000 & 5.000 \\
75\% Percentile & 8.000 & 6.000 & 5.750 & 7.000 & 8.000 & 6.000 \\
Lower 95\% CI of mean & 5.145 & 4.290 & 3.746 & 4.987 & 5.521 & 4.070 \\
Upper 95\% CI of mean & 6.330 & 5.146 & 4.754 & 5.988 & 6.504 & 5.196 \\
\hline
\end{tabular}
different kinds of anxiety as after-effects of COVID-19
Table 2 Probability of having 
Table 3 Probability of having anxiety as after-effects of COVID-19 in various genders

\begin{tabular}{llll}
\hline Determinants & \multicolumn{2}{l}{ Gender } \\
\cline { 2 - 4 } & Female & Male & Transgender \\
\hline No. of values & 81 & 81 & 72 \\
Mean & 6.556 & 6.543 & 5.153 \\
25\% Percentile & 5.000 & 5.000 & 4.000 \\
Median & 7.000 & 7.000 & 5.000 \\
75\% Percentile & 8.000 & 7.000 & 7.000 \\
Lower 95\% CI of mean & 6.133 & 6.188 & 4.674 \\
Upper 95\% CI of mean & 6.978 & 6.898 & 5.632 \\
\hline
\end{tabular}

were aware about the COVID-19 and have knowledge of anxiety disorders. Ninety-five percent medical practitioners were in the view to have anxiety as after-effect of COVID19 (Fig. 2). To quantify the probability of anxiety as repercussion of COVID-19, questions with the response score 1-10 (each point of score equivalent to $10 \%$ ) were given in the questionnaire. The study revealed that the possibility of having generalized anxiety disorders, panic disorder, obsessive-compulsive disorder, post-traumatic stress disorder, social anxiety disorder and specific phobia as repercussion of COVID-19 was found 57, 47, 42, 55, 60 and 46\%, respectively (Table 2, Fig. 3). Statistical data indicate that there are maximum chances to have social anxiety and post-traumatic stress anxiety disorder as a consequence of COVID-19. Data mentioned in Table 3 and Fig. 4 reveal that both female and male genders have equal chances $(65 \%)$, whereas transgender has lesser chances (51\%) to have anxiety as after-effect of COVID-19. Medical practitioners (75\% among all) had opinion that patients up to age group of 10 years was not affected, but on the other hand, age group of more than 19 years were affected by anxiety disorder as a consequence of COVID-19. Moreover, maximum chances of having anxiety as repercussion of COVID-19 are in the population 50-70 years of age (Table 4, Fig. 5). Study conducted on the opinion of medical practitioners indicates the chances of having anxiety disorders to the human population as a repercussion of COVID-19. The outcomes of study suggest planning of the control measures to manage the anxiety disorder after control of COVID-19.

Table 4 Probability of having anxiety as after-effects of COVID-19 in various age group

\begin{tabular}{llllllll}
\hline Determinants & \multicolumn{7}{l}{ Age groups } \\
\cline { 2 - 8 } & Up to 5 year & $6-10$ years & $11-18$ years & 19-30 years & 31-50 years & 51-70 years & Above 70 year \\
\hline No. of values & 76 & 76 & 79 & 81 & 81 & 81 & 80 \\
Mean & 1.737 & 2.684 & 4.405 & 5.716 & 6.506 & 7.321 & 7.050 \\
25\% Percentile & 0.0 & 0.0 & 3.000 & 5.000 & 5.000 & 7.000 & 6.000 \\
Median & 0.5000 & 2.500 & 4.000 & 6.000 & 6.000 & 8.000 & 8.000 \\
75\% Percentile & 3.000 & 4.000 & 5.000 & 7.000 & 7.000 & 8.000 & 9.000 \\
Lower 95\% CI of mean & 1.160 & 2.061 & 3.991 & 5.337 & 6.125 & 6.966 & 6.559 \\
Upper 95\% CI of mean & 2.314 & 3.308 & 4.820 & 6.095 & 6.888 & 7.676 & 7.541 \\
\hline
\end{tabular}

Fig. 2 Opinion of medical practitioners to have anxiety as after-effect of COVID-19

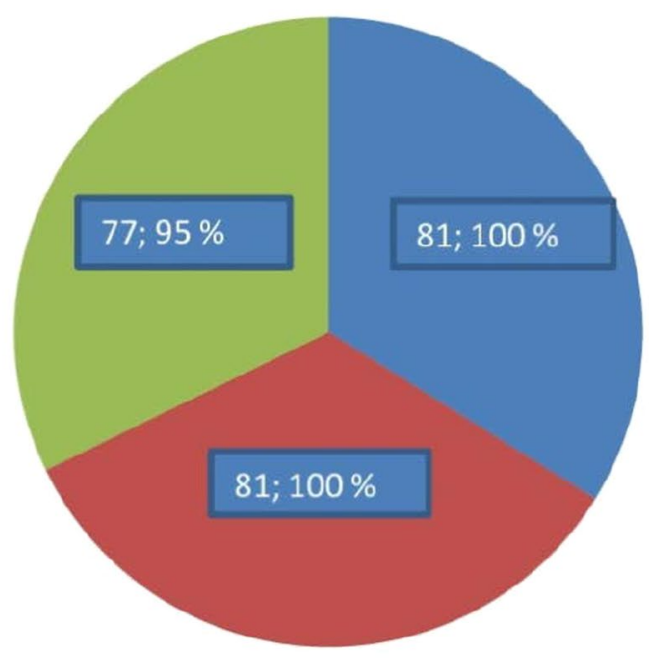

Medical Practitioners aware with COVID-19

Medical Practitioners aware with anxiety disorders

Medical Practioners with the view to have anxiety as after-effect of COVID-19 


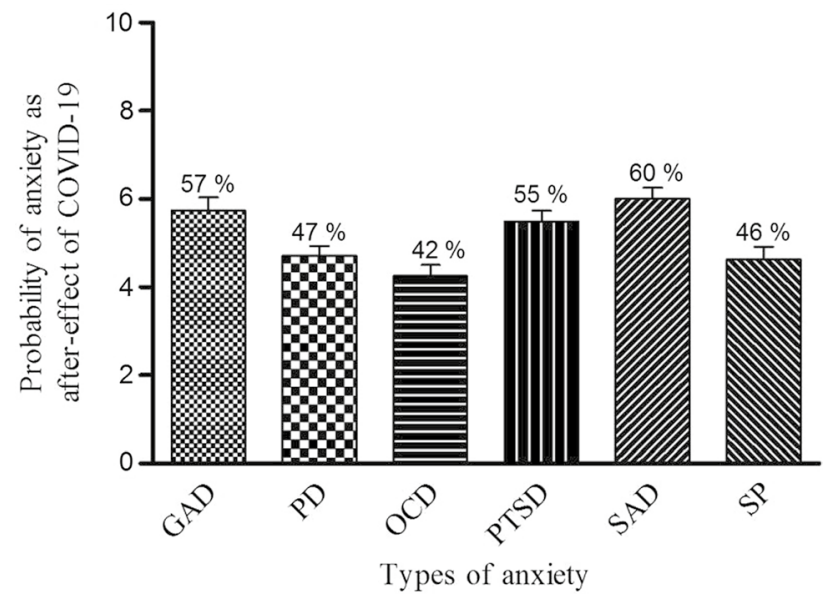

Fig. 3 Probability of having different kinds of anxiety as after-effects of COVID-19

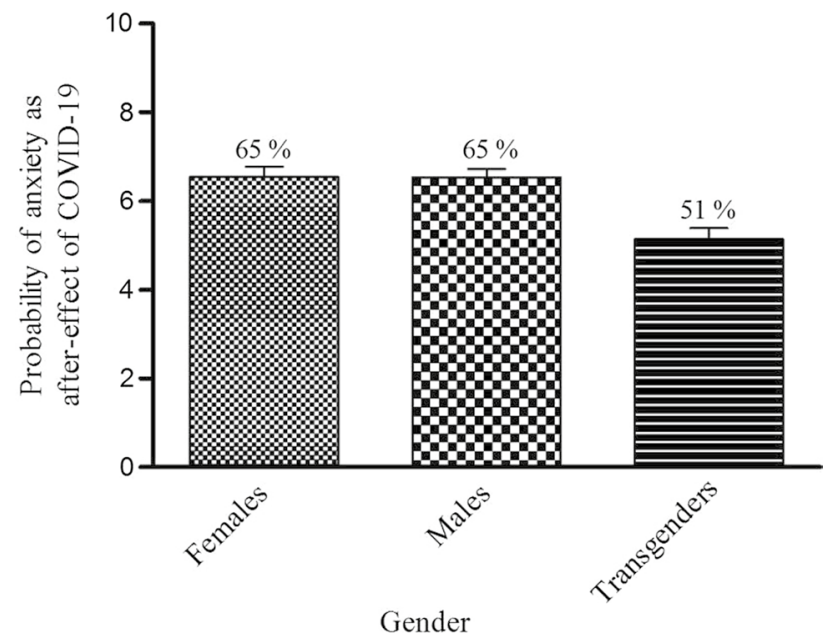

Fig. 4 Probability of having anxiety as after-effects of COVID-19 in various genders

\section{Conclusions and Recommendations}

The present study concludes that anxiety might occur as one of the after-effects of COVID-19. There are more possibilities to have social anxiety and post-traumatic stress anxiety disorder as after-effects of COVID-19. Female and male genders have equal chances, whereas transgender has lesser chances to have anxiety disorders as a consequence of COVID-19. Moreover, there are more chances of having anxiety to the population of above 50 years of age group. Based on the findings of the present study, authors recommend to various health agencies and regulatory bodies to have a strategic plan to handle the patients having anxiety disorder as a consequence of COVID-19.

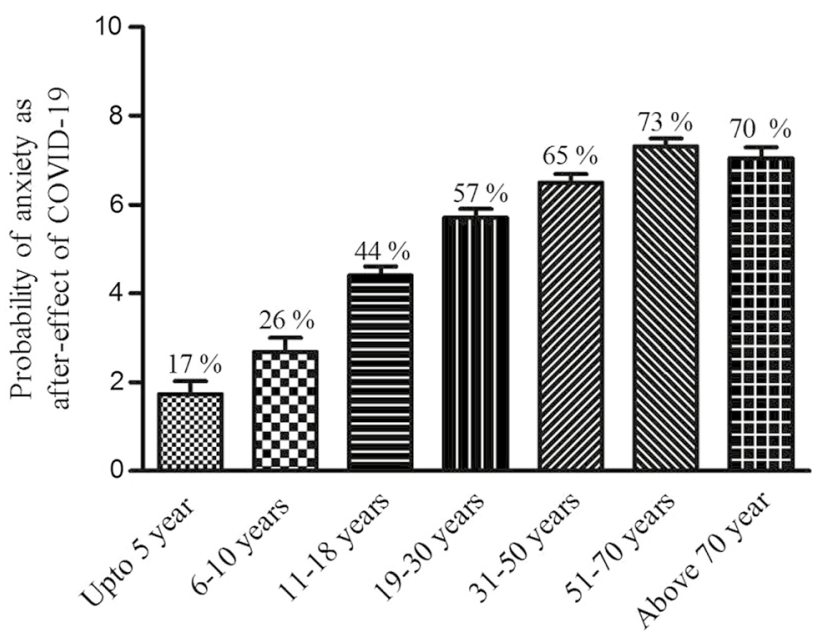

Age

Fig. 5 Probability of having anxiety as after-effects of COVID-19 in various age groups

Acknowledgements Authors acknowledged Career Point University, Hamirpur, Himachal Pradesh, for providing non-technical support.

Funding This investigation didn't get any funding from outer agency.

\section{Compliance with Ethical Standards}

Conflict of interest The authors declare no conflicts of interest.

\section{References}

1. Sarason, I.G.; Srarson, B.R.: The Problem of Maladaptive Behavior- Abnormal Psychology, 8th edn. Prentice Hall of India, New Delhi (2000)

2. McNaughton, N.: Fear, anxiety and their disorders: past, present and future neural theories. Psychol. Neurosci. 4, 173-181 (2011)

3. Shri, R.: Anxiety: causes and management. J. Behav. Sci. 5, 100-118 (2010)

4. Lee, L.A.; David, A.S.; Mason, A.E.; Law, R.W.: Attachment anxiety, verbal immediacy, and blood pressure: results from a laboratory analog study following marital separation. Pers. Relatsh. 18, 285-301 (2011)

5. Ritchie, H. and Roser, M.: Anxiety Disorders. https://ourwo rldindata.org/mental-health\#anxiety-disorders (2020). Accessed from 11 Aug 2020.

6. Raakhee, A.S.; Aparna, N.: A study on the prevalence of anxiety disorders among higher secondary students. GESJ Educ. Sci. Psychol. 1, 33-37 (2011)

7. Baldessarini, R.J.: Drugs and the treatment of psychiatric disorders. In: Hardman, J.G.; Limbird, L.E. (Eds.) Goodman and Gilman's: The Pharmacological Basis of Therapeutics, 10th edn. McGraw-Hill, New York (2001)

8. Kessler, R.C.; Berglund, P.; Demler, O.; Jin, R.; Merikangas, K.R.; Walters, E.E.: Lifetime prevalence and age-of-on set distributions of DSM-IV disorders in the national comorbidity survey replication. Arch. Gen. Psychiatry 62, 593-602 (2005) 
9. Marcks, B.A.; Weisberg, R.B.; Edelen, M.O.; Keller, M.B.: The relationship between sleep disturbance and the course of anxiety disorders in primary care patients. Psychiatry Res. 178, 487-492 (2010)

10. Wald, J.; Taylor, S.: Efficacy of interoceptive exposure therapy combined with trauma- related exposure therapy for posttraumatic stress disorder, a pilot study. J. Anxiety Disord. 21, 1050-1060 (2007)

11. Osman, A.; Freedenthal, S.; Gutierrez, P.M.; Wong, J.L.; Emmerich, A.; Lozano, G.: The anxiety depression distress inventory-27 (ADDI-27): a short version of the mood and anxiety symptom questionnaire-90. J. Clin. Psychol. 67, 591-608 (2011)

12. Book, S.W.; Thomas, S.E.; Dempsey, J.P.: Social anxiety impacts willingness to participate in addiction treatment. Addict. Behav. 24, 474-476 (2009)
13. Ollendick, T.H.; Öst, L.G.; Reuterskild, L.; Costa, N.: Comorbidity in youth with specific phobias: impact of comorbidity on treatment outcome and the impact of treatment on comorbid disorders. Behav. Res. Ther. 48, 827-831 (2010)

14. Portman, M.E.: Generalized anxiety disorder across the lifespan: an integrative approach. Cogn. Behav. Ther. Book Rev. 7, 1-3 (2011)

15. World Health Organization: Coronavirus disease (COVID-19) pandemic. https://www.who.int/emergencies/diseases/novel-coron avirus-2019? (2020). Accessed from 11 Aug 2020.

16. Hritcu, L.; Ionita, R.; Postu, P.A.; Gupta, G.K.; Turkez, H.; Lima, T.C.; Carvalho, C.U.S.; de Sousa, D.P.: Antidepressant flavonoids and their relationship with oxidative stress. Oxid. Med. Cell. Longev. 5762172, 1-18 (2017) 